\title{
Dissolved organic matter (DOM) in recycled leachate of bioreactor landfill
}

\author{
Pin-jing $\mathrm{He}^{a}$,* , Jun-feng Xue ${ }^{a}$, Li-ming Shao ${ }^{a}$, Guo-jian $\mathrm{Li}^{a}$, Duu-Jong Lee ${ }^{b}$ \\ ${ }^{a}$ State Key Laboratory of Pollution Control and Reclamation, Tongji University, 1239 Siping Road, Shanghai 200092, PR China \\ ${ }^{\mathrm{b}}$ Department of Chemical Engineering, National Taiwan University, Taipei 10617, Taiwan
}

\section{A R T I C L E I N F O}

Article history:

Received 5 April 2005

Received in revised form

2 December 2005

Accepted 31 January 2006

\section{Keywords:}

Recirculated leachate

Fulvic acids

Humic acids

Molecular weight

Coagulation

Electrolysis

\begin{abstract}
A B S T R A C T
Landfill leachate needs sufficient treatment before safe disposal. Bioreactor landfill technology could effectively degrade the organic matters in recirculated leachate, hence leaving a leachate stream of low biodegradability. This study characterized the dissolved organic matter (DOM) in the leachate from simulated bioreactor landfill columns with or without presence of trace oxygen. The removal efficiencies of this DOM using coagulation-sedimentation or electrolysis processes were demonstrated.

Recirculated leachates were sampled from the simulated landfill columns applying conventional mode, intermittent-aeration mode, and natural aeration mode, whose DOM was fractionated into humic acids (HA), fulvic acids (FA) and hydrophilic fractions (HyI) by the XAD-8 resin combined with the cation exchange resin method. The recirculated leachate had low BOD/COD ratio, high humic substances contents, and high aromatic content. Their HA fraction comprised mainly large molecules ( $>10 \mathrm{kDa})$, while the FA and HyI were composed of smaller molecules ( $<50 \mathrm{k}$ and $<4 \mathrm{kDa}$, respectively). With the presence of oxygen, the TOC contents and the contents of HA, FA and HyI in leachate reduced, with FA and HyI fractions of molecular weight (MW) lower than $4 \mathrm{kDa}$ more readily degraded. The organic matters left in leachates from intermittent-aeration mode and natural aeration mode were of low biodegradability. It was tested in the following sections the effects of coagulation-sedimentation process and of electrolysis process on the removal of residual DOM in recirculated leachate.

Coagulation-sedimentation tests revealed that poly ferric sulphate (PFS) could remove more COD $(58.1 \%)$ from leachate than polyaluminum chloride (PACl) $(22.9 \%)$, particularly on the HA fraction with $\mathrm{MW}>10 \mathrm{kDa}$. Coagulation-sedimentation could not remove most of HyI in leachate. Furthermore, the corresponding BOD/COD ratio was not improved through coagulation. Electrolysis test could also effectively removed HA of MW $>10 \mathrm{kDa}$. However, the biodegradability of treated effluent considerably was improved. The electrolysis could decompose high MW substances and increase biodegradability of recirculated leachate from bioreactor landfill.
\end{abstract}

(c) 2006 Elsevier Ltd. All rights reserved.

*Corresponding author. Tel.: +862165986104; fax: +862165986104.

E-mail address: solidwaste@mail.tongji.edu.cn (P.-j. He).

0043-1354/\$ - see front matter (c 2006 Elsevier Ltd. All rights reserved.

doi:10.1016/j.watres.2006.01.048 


\section{Introduction}

Leachate contains vast amount of hazardous substances, which needs sufficient treatment before safe disposal (Amokrane et al., 1997). Bioreactor landfill technology uses leachate recirculation and other controlled methods to strengthen the microorganism process of landfill sites, which can accelerate degradation of organic matters both in solid waste and in leachate (He et al., 2005). However, leachate after recirculation through landfill still could not be discharged directly to the receiving water body owing to the high residual bio-refractory compounds.

Studies on leachate treatment processes, such as the use of coagulation-sedimentation, reverse osmosis, advanced oxidation process, revealed the close correlation between the characteristics of dissolved organic matter (DOM) in leachates and the treatment performance (Baumgarten and Seyfried, 1996; Tsai et al., 1997; Yoon et al., 1998; Zhang and Huang, 2002). DOM is often regarded as a continuum of organic molecules of different molecular weights (MW) and structures that could pass through $0.45-\mu \mathrm{m}$ filtration membranes, including low MW substances like amino acids, carbohydrates, organic acids, and some high MW substances like humic substances (Kalbitz et al., 2000). DOM could be further fractionated into humic acids (HA), fulvic acids (FA) and hydrophilic (HyI) fractions according to their hydrophilichydrophobic interactions (Christensen et al., 1998; Wang and Zhou, 2003).

The characterization of DOM in landfill leachate can guide the selection of treatment process and set up ground for assessment on environment risk of leachate (Thornton et al., 2000; Leenheer and Croue, 2003; Li et al., 2003). Kang et al. (2002) characterized the characteristics of humic substances (HS) in three landfill leachates of different waste age. However, to the authors' best knowledge, there exists no comprehensive studies in pertinent literature on the characterization of three fractions of DOM, HA, FA, and HyI, in landfill leachate, particularly in recycled leachate of bioreactor landfills.

Biological treatments degrade organic matters of low MW (Luo et al., 1998). Physical-chemical methods are preferred for handling the refractory organics of high MW. The coagulation-sedimentation was found effective to remove hydrophobic organic matters of high MW and of high aromatic extent (Laine et al., 1990; Luo et al., 1998; Edzwald and Tobiason, 1999). Coagulation was also noted to be effective for treating leachate from old landfill of low BOD/COD ratio, but be inadequate for coagulating leachate from young landfill of higher BOD/COD ratio (Amokrane et al., 1997; Tatsi et al., 2003). On the other hand, electrolysis process could markedly reduce COD and $\mathrm{NH}_{3}-\mathrm{N}$ of landfill leachate (Chiang et al., 1995; Cossu et al., 1998; Vlyssides et al., 2003). Chiang et al. (1997) revealed that the electrolysis using $\mathrm{Cl}^{-}$as supporting electrolyte could degrade organic matters of both high and low MW.

This paper characterized the DOM in leachate collected from simulated landfill columns filled with refuse of typical compositions of that produced in Shanghai City, China. The simulated columns were landfill bioreactors operated at three different modes: conventional mode, intermittent-aeration mode, and natural aeration mode. The hydrophilic-hydrophobic characteristics and the MW distributions were used to fractionate the DOM in leachates thus produced. It was also explored how two commonly applied treatment processes, coagulation-sedimentation and electrolysis, affected the DOM distributions in the landfill leachates.

\section{Materials and methods}

\subsection{The samples}

The samples were collected from three simulated columns in laboratory. The refuse in the simulated columns had the same compositions of that collected in Shanghai city, China (He et al., 2003). Fig. 1 shows the schematic of the three columns (Yu et al., 2004). Each simulated column had a diameter of $40 \mathrm{~cm}$ and height $220 \mathrm{~cm}$, providing a working volume of $210 \mathrm{l}$. Three simulated columns were all placed in an attemperator to keep temperature at $30^{\circ} \mathrm{C} \pm 2{ }^{\circ} \mathrm{C}$. Three reservoir tanks (40l each) were used to collect leachate from the simulated column.

During the first six weeks of testing, all three columns were kept at anaerobic condition with leachate recycled at $3 \mathrm{ld}^{-1}$. Leachate samples were collected from the outlets of these simulated columns at fixed time intervals (all termed as LN). Excess leachate was collected in each of the reservoir tanks, reaching a volume of around 301 at the end of week 6 .

For the first simulated column, the leachate was pretreated by an aerobic sequencing batch reactor (SBR) during week $7-18$ before recycled back to the column at a rate of $31 \mathrm{~d}^{-1}$. At the end of week 18 stable methanogenic reactions had been established stably in the column, and the leachate collected was directly recycled back to the column onwards (Zhang et al., 2004). The leachate samples collected from the first column were termed as L1.

Since the week 7 the second and the third columns adopted intermittent-aeration mode (mechanically aerated at 0.29-0.57l-air kg ${ }^{-1}$ refuse $d^{-1}$ with 12-h intervals, Fig. 1b) and natural aeration mode (natural convection through a central ventilation pipe of diameter $5 \mathrm{~cm}$, Fig. 1c), respectively (Yu et al., 2004). The leachate was collected from the individual reservoir tank and recirculated at $3 \mathrm{ld}^{-1}$ back to the columns. Samples of leachate were taken from columns 2 and 3 and were termed as L2 and L3, respectively.

The leachate characteristics from all three simulated columns reached a stable state at week 78. Leachate evaporation loss was minimal since close system for leachate was adopted during weeks 18-78. No water was added in the reservoir tank to make up the leachate loss.

Table 1 lists the characteristic ranges of leachates LN, and L1-L3 within 4 weeks after stabilization. The fresh leachate LN was strong liquor, with COD of $36900-66900 \mathrm{mgl}^{-1}$. Leachate recirculation through simulated columns considerably reduced the COD value to $526-1480 \mathrm{mgl}^{-1}$. The L2 and L3 had lower $\mathrm{COD}$ and $\mathrm{NH}_{3}-\mathrm{N}$ levels compared with those in L1. Nonetheless, the recirculated leachate still exhibited a COD exceeding the discharge standards to receiving water body (State Environmental Protection Administration of China, 1997), but the low BOD/COD ratios (0.05-0.1) of the collected recirculated leachates indicated that non-biological 


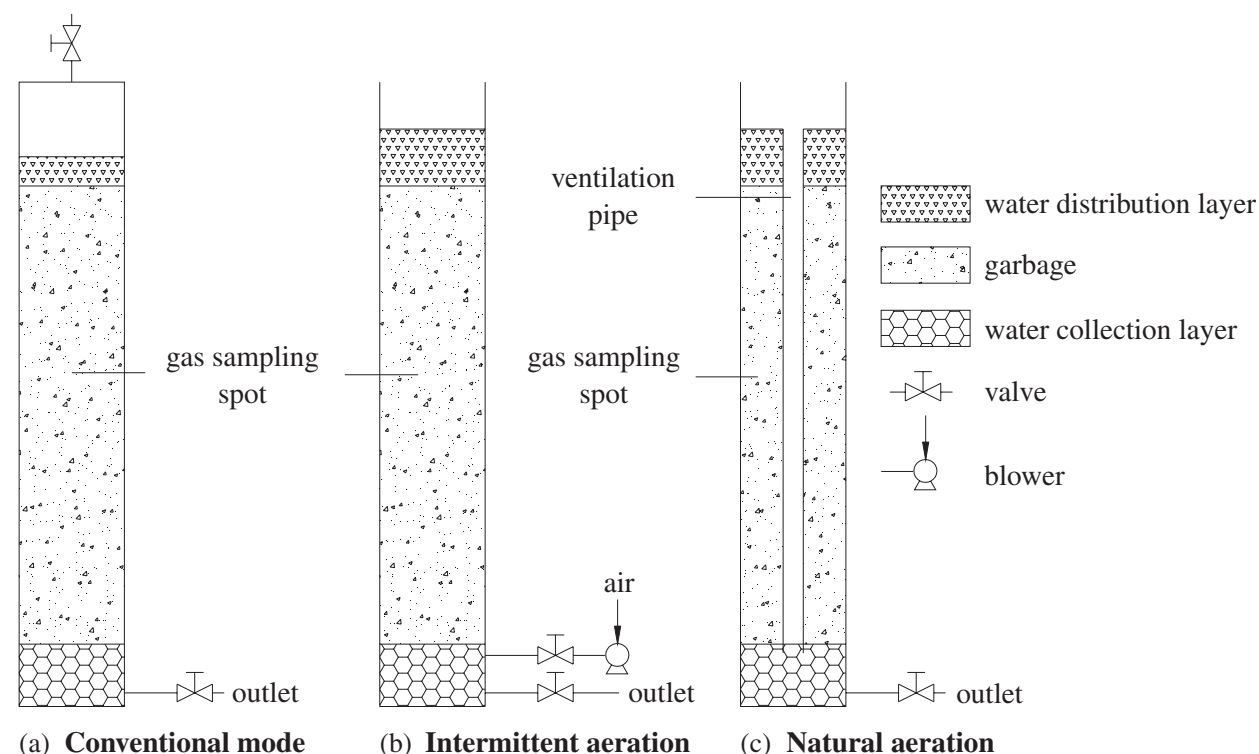

(a) Conventional mode

(b) Intermittent aeration

(c) Natural aeration

Fig. 1 - The schematic of the three simulated landfill columns.

Table 1 - The characteristics of leachate samples collected from the simulated columns

\begin{tabular}{|c|c|c|c|c|}
\hline \multirow[t]{2}{*}{ Samples } & \multirow[t]{2}{*}{ LN } & L1 & L2 & L3 \\
\hline & & Conventional & Intermittent aeration & Natural aeration \\
\hline $\mathrm{TOC} /\left(\mathrm{mgl}^{-1}\right)$ & $12300-20900$ & $262-437$ & $187-312$ & $171-285$ \\
\hline $\mathrm{COD} /\left(\mathrm{mgl}^{-1}\right)$ & $36900-66900$ & $890-1480$ & $543-905$ & $526-878$ \\
\hline $\mathrm{BOD} /\left(\mathrm{mgl}^{-1}\right)$ & $22300-48100$ & $45-170$ & $20-95$ & $25-90$ \\
\hline $\mathrm{TP} /\left(\mathrm{mgl}^{-1}\right)$ & $39.6-54.0$ & $4.1-5.6$ & $3.4-4.7$ & $1.7-2.2$ \\
\hline $\mathrm{NH}_{3}-\mathrm{N} /\left(\mathrm{mgl}^{-1}\right)$ & $878-1140$ & $618-935$ & $112-187$ & $93-154$ \\
\hline $\mathrm{Cl}^{-} /\left(\mathrm{mgl}^{-1}\right)$ & $1710-3520$ & $1210-3030$ & $1130-3560$ & $1320-3200$ \\
\hline $\mathrm{pH}$ & $5.5-6.1$ & $7.7-8.5$ & $7.8-8.6$ & $7.9-8.8$ \\
\hline Conductivity & & & & \\
\hline$/\left(10^{3} \mu \mathrm{Scm}^{-1}\right)$ & $23.5-28.1$ & $21.6-30.2$ & $24.1-31.0$ & $23.7-25.2$ \\
\hline Alkalinity & & & & \\
\hline$\left(1 / 2 \mathrm{CaCO}_{3}\right) /\left(\mathrm{gl}^{-1}\right)$ & $6.7-9.1$ & $3.2-3.7$ & $2.3-3.1$ & $3.3-4.1$ \\
\hline Color/times & $4000-6000$ & $500-800$ & $400-600$ & $400-600$ \\
\hline $\mathrm{Na}^{+}\left(\mathrm{mgl}^{-1}\right)$ & $1230-2070$ & $1200-2000$ & $1200-2000$ & $1200-2000$ \\
\hline $\mathrm{K}^{+}\left(\mathrm{mgl}^{-1}\right)$ & $1010-1520$ & $1000-1500$ & $1000-1500$ & $1000-1500$ \\
\hline
\end{tabular}

treatment processes were required for subsequent treatment stages of leachate.

The DOM for LN collected at week 6 and those for L1-L3 collected at week 78 were isolated and analyzed. In the subsequent coagulation-sedimentation and electrolysis studies, the testing sample was L1 at week 78.

\subsection{Experimental methods}

\subsubsection{Isolation and characterization of DOM}

Methods described by Thurman and Malcolm (1981) and Christensen et al. (1998) were adopted herein for speciation and purification of HA, FA, and HyI fractions of organic matters in leachate (Fig. 2). Based on this scheme, the DOM in leachate was fractionated into HA, FA, and HyI fractions, and the HA + FA was denoted as HS.
Amberlite XAD-8 resin was obtained from Rohm and Haas Co. (Philadelphia, USA) and 732 cation exchange resin was obtained from Shanghai Huizhi Co. (Shanghai, China). The XAD- 8 resin was first soaked in $0.1 \mathrm{M} \mathrm{NaOH}$ for $3 \mathrm{~d}$ and then was sequentially extracted for $8 \mathrm{~h}$ in each of the following Soxhlet-Extraction solutions: methanol, diethyl ether, acetone, and methanol. After extraction, the resin was air-dried in the ventilation chamber. The clean resin was soaked in distilled water before use. Before testing, this resin was washed with distilled water until the effluent TOC approached zero.

The 732 cation resin was first soaked in distilled water to make it swollen and then was soaked in $2-4 \% \mathrm{NaOH}$ to remove the organic matters. It was finally soaked in $4-5 \% \mathrm{HCl}$ to remove compounds including $\mathrm{Fe}^{3+}$. The clean resin was washed by distilled water until the effluent $\mathrm{pH}$ was close to 7.0. 


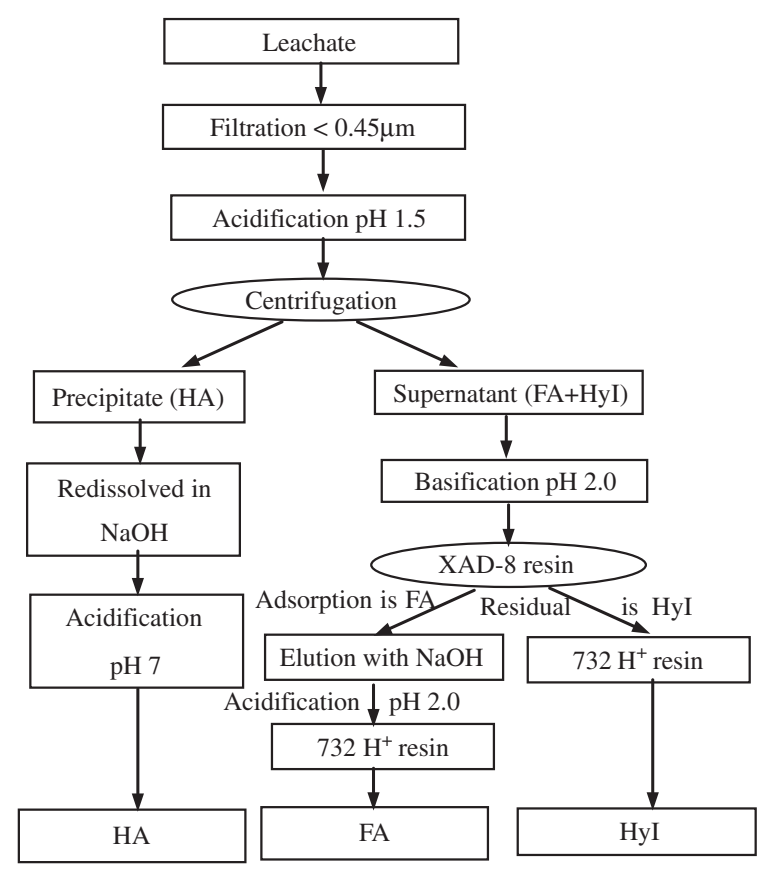

Fig. 2 - Separation and purification procedures to fractionate DOM in leachate.

The MW distributions of HA, FA, and HyI fractions were characterized using membrane filtration method. The SCM serial filtration implement and HM serial flat ultra-filtration membrane from Separation Engineering R\&D Center, Shanghai Institute of Nuclear Studies (Shanghai, China) were used in this work to provide MW cutoffs at $100 \mathrm{k}, 50 \mathrm{k}, 10 \mathrm{k}, 4 \mathrm{k}$ and $1 \mathrm{kDa}$, respectively.

\subsubsection{Analyses}

A TOC/TN analyzer (multi N/C 3000, Analytik Jena AG, Germany) measured the total organic carbon (TOC) and dissolved organic carbon (DOC) of samples, with the latter pre-filtered using a $0.45-\mu \mathrm{m}$ membrane. The UV analysis for the leachate samples was conducted by a 732 spectraphotometer (Precision \& Scientific instrument Co., Shanghai, China). The specific ultraviolet absorbance at wavelengths $254 \mathrm{~nm}\left(\right.$ SUVA $\left._{254}\right)$ was defined as UV absorbance at $254 \mathrm{~nm}$ divided by DOC (Li et al., 1998).

\subsubsection{The coagulation test}

The recirculated leachate L1 and coagulants, poly ferric sulphate (PFS) or polyaluminum chloride (PACl), were added to 1-l beakers in jar tester (MY3000-6C, Hubei, China), stirred at $200 \mathrm{rpm}$ for $1 \mathrm{~min}$ and then at $60 \mathrm{rpm}$ for $15 \mathrm{~min}$. The initial $\mathrm{pH}$-values of samples were adjusted to 5.0. The supernatant after $30 \mathrm{~min}$ settling were withdrawn at $2 \mathrm{~cm}$ from water surface for DOM analysis. The doses of PFS and PACl were $1.96 \mathrm{mmoll}^{-1}$ as $\mathrm{Fe}$ and $2.35 \mathrm{mmoll}^{-1}$ as Al, respectively, which were determined "optimal" based on preliminary jar tests.

\subsubsection{The electrolysis test}

The electrolysis apparatus was a 1-l magnetic stirred electrochemical cell installed with five electrodes: three stainless

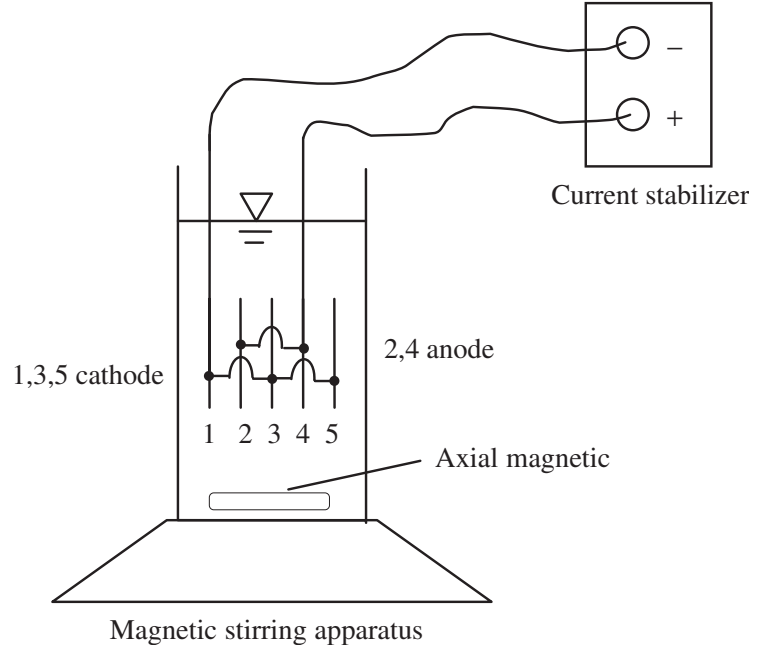

Fig. 3 - Schematic of the electrolysis reactor.

steel sheets as cathodes and two titanium sheets coated with $\mathrm{TiO}_{2}-\mathrm{IrO}_{2}-\mathrm{RuO}_{2}$ as the anodes (Fig. 3). The total area of anode was $100 \mathrm{~cm}^{2}$. The gap between every two neighboring electrodes was $10 \mathrm{~mm}$. A current stabilizer provided an electric current density of $100 \mathrm{~mA} \mathrm{~cm}^{-2}$ over electrolysis tests. The $\mathrm{Cl}^{-}$concentration of the leachate was adjusted to $5000 \mathrm{mgl}^{-1}$ by $\mathrm{NaCl}$ prior to electrolysis test. The recirculated leachate L1 with initial $\mathrm{pH} 8$ was electrolyzed.

\section{Results and discussion}

\subsection{The DOM in leachate}

\subsubsection{DOM contents}

The total organic carbon (TOC) concentrations and the HA, FA, and HyI fractions of DOM in LN and L1-L3 were listed in Table 2. The TOC concentrations in leachate followed: LN $\gg$ L1 $>$ L2, L3. The DOC in recycled leachates through the bioreactor landfill accounted for $89.5 \%, 89.3 \%$ and $85.6 \%$ of TOC in L1-L3, respectively. Restated, the DOM comprised a majority of organic substances in the leachates.

The TOC of leachate LN was mainly composed of HyI fraction $(77 \% \mathrm{w} / \mathrm{w})$. After recirculation through bioreactor landfill, the HyI fraction considerably declined from $11700 \mathrm{mgl}^{-1}$ for LN to $87-115 \mathrm{mgl}^{-1}$ for L1-L3, indicating that the degradation reaction in the simulated column could remove $99 \%$ of HyI fraction of DOM from the leachate. The removal of HA and FA fractions when recirculated through landfill were also significant: for the former, 87 to $12-20 \mathrm{mgl}^{-1}$; and for the latter, from 3390 to $96-178 \mathrm{mgl}^{-1}$. As the trend noted for TOC in leachates, the HA, FA and HyI contents in DOM were all higher for L1 than L2 and L3. This observation revealed that the supply of limited oxygen in anaerobic landfill was beneficial to the degradation of organic matters. In all recirculated leachates, FA $>\mathrm{HyI}>\mathrm{HA}$, and the humic substances accounted for $63 \% \mathrm{w} / \mathrm{w}$ in L1 and about $56 \% \mathrm{w} / \mathrm{w}$ in L2 and L3. 
Table 2 - Concentrations of organic carbon of HA, FA and HyI in leachate samples

\begin{tabular}{llcccc}
\hline Samples & & LN & L1 & L2 & L3 \\
\hline TOC $\left(\mathrm{mgl}^{-1}\right)$ & & 15700 & 349 & 245 & 228 \\
& HA & 87 & 20 & 13 & 12 \\
DOC $\left(\mathrm{mgl}^{-1}\right)$ & FA & 3390 & 178 & 115 & 96 \\
& HyI & 11700 & 115 & 95 & 87 \\
DOC/TOC (\%) & & 96.9 & 89.5 & 89.3 & 85.6 \\
& & & & & \\
\hline
\end{tabular}

Table 3 - The SUVA 254 of HA, FA and HyI fractions from leachates samples $\left(\mathbf{m g}^{-1} \mathbf{m}^{-1}\right)$

\begin{tabular}{lcccc}
\hline Fractionation & LN & L1 & L2 & L3 \\
\hline HA & 1.08 & 4.34 & 4.85 & 4.55 \\
FA & 0.24 & 3.11 & 3.90 & 3.76 \\
HyI & 0.06 & 1.60 & 1.83 & 1.72 \\
\hline
\end{tabular}

\subsubsection{Aromatic extent of DOM in leachates}

The SUVA 254 correlated with the aromatic extent of leachate: the higher the $\mathrm{SUVA}_{254}$, the greater the aromatic content of organic matters (Dong et al., 2001). The SUVA $_{254}$ for HA, FA and $\mathrm{HyI}$ fractions obtained in leachate samples were listed in Table 3.

In all tested leachate samples, the $\mathrm{SUVA}_{254}$ followed $\mathrm{HyI}<\mathrm{FA}<\mathrm{HA}$ and $\mathrm{LN}<\mathrm{L} 1<\mathrm{L} 2<\mathrm{L} 3$. For the former sequence, the SUVA $_{254}$ of HA and FA were much higher than HyI, indicating that the humic substances contained higher percentage of bio-refractory compounds. The latter sequence simply indicated that aerobic processes in the simulated columns, particularly in natural aeration mode (L3), removed most easily degradable, non-aromatic, organic substances. The relative high $\mathrm{SUVA}_{254}$ in recirculated leachate correlated with the corresponding low BOD/COD ratios noted in Table 1. Further treatment on recirculated leachate, particularly those with the presence of oxygen, relied on physical/chemical processes. The aromatic extents of the HA, the FA and the HyI fractions in recirculated leachate from the intermittent aeration column (L2) and natural aeration column (L3) was high compared to that from aerobic-anaeration column (L1).

\subsubsection{Molecular weight distributions of DOM in leachates} Membrane filtration technique probed the MW distributions of the HA, FA and HyI fractions of LN, and L1-L3. Table 4 lists the DOC contents of HA, FA and HyI fractions of LN at different MW. Fig. 4 shows the MW distributions of HA, FA and HyI fractions of L1-L3 based on the DOC contents. Fig. 5 revealed the percentage distributions of the MW of organic matters in recirculated leachates.

LN mainly comprised HyI and FA fractions with $\mathrm{MW}<1 \mathrm{k} \mathrm{Da}$ (Table 4). After leachate recirculation, the HA fraction mainly comprised large molecules, while the FA and HyI were composed of small molecules $(<10-50 \mathrm{k}$ and $<1 \mathrm{kDa}$, respectively) (Fig. 4). Correlated with the observations noted in
Table 4 - The DOC contents of HA, FA and HyI fractions from leachate $\mathrm{LN}$ in different MW ranges

\begin{tabular}{lccc}
\hline $\begin{array}{l}\text { Molecular weight } \\
\text { (Da) }\end{array}$ & HA & FA & HyI \\
\cline { 2 - 4 } & $\begin{array}{c}\mathrm{DOC} \\
\left(\mathrm{mgl}^{-1}\right)\end{array}$ & $\begin{array}{c}\mathrm{DOC} \\
\left(\mathrm{mgl}^{-1}\right)\end{array}$ & $\begin{array}{c}\mathrm{DOC} \\
\left(\mathrm{mgl}^{-1}\right)\end{array}$ \\
\hline$>100 \mathrm{k}$ & 15 & 41 & 85 \\
$50-100 \mathrm{k}$ & 17 & 43 & 104 \\
$10-50 \mathrm{k}$ & 9 & 63 & 112 \\
$4-10 \mathrm{k}$ & 6 & 75 & 126 \\
$1-4 \mathrm{k}$ & 16 & 113 & 175 \\
$<1 \mathrm{k}$ & 24 & 3060 & 11100 \\
\hline
\end{tabular}

preceding sections, the HyI fraction was readily degraded over leachate recirculation. Moreover, the FA and HyI fractions with $\mathrm{MW}<4 \mathrm{k} \mathrm{Da}$ were more readily removed with the presence of oxygen (Fig. 4).

In the recycled leachates, HA accounted for $75 \%$ organic matters with MW $>4 \mathrm{kDa}$, FA for $64 \%$ organic matters with MW between $1 \mathrm{k}$ and $50 \mathrm{kDa}$, while HyI for $67 \%$ organic matters with $\mathrm{MW}<4 \mathrm{kDa}$ (Fig. 5).

In recirculated leachate, the $\mathrm{SUVA}_{254}$ for all three DOM fractions decreased with decreasing MW. The $\mathrm{SUVA}_{254}$ for HyI ranged $1.37-1.87 \mathrm{l} \mathrm{mg}^{-1} \mathrm{~m}^{-1}$ (Table 5). Meanwhile, most organic matters with MW $>4 \mathrm{k}$ Da had higher $\mathrm{SUVA}_{254}$ for L2 and $\mathrm{L} 3$ than L1, and this trend reversed when $\mathrm{MW}<4 \mathrm{kDa}$.

\subsection{Treatment processes of recirculated leachate}

The three recirculated leachate samples from bioreactor landfills with or without trace oxygen had DOMs of distinct characteristics. The recirculated leachates L1-L3 had low biodegradability (low BOD/COD ratios in Table 1), high humic substances contents (55-63\% in Table 2), and high aromatic content (high $\mathrm{SUVA}_{254}$ in Table 3). Their HA fraction comprised mainly large molecules $(>10 \mathrm{kDa})$, while the FA and HyI were composed of small molecules $(<50 \mathrm{k}$ and $<4 \mathrm{kDa}$, respectively). Especially with the presence of oxygen, the TOC contents and the contents of HA, FA and HyI in leachate reduced, with FA and HyI fractions of MW lower than $4 \mathrm{k}$ more readily degraded. The organic matters left in L2 and L3 were of lower biodegradability than in L1. It was tested in the following sections the effects of coagulation-sedimentation process and of electrolysis process on the removal of residual DOM in recirculated leachate.

\subsubsection{Coagulation-sedimentation}

Coagulation-sedimentation tests revealed that the COD removal ratio from leachate L1 was $58.1 \%$ by PFS (from $1720 \mathrm{mgl}^{-1}$ to $720 \mathrm{mgl}^{-1}$ ) and $22.9 \%$ by PACl (from $1720 \mathrm{mgl}^{-1}$ to $\left.1325 \mathrm{mgl}^{-1}\right)$. PFS appeared more efficient for organic substance removal than PACl.

Fig. 6 shows the removal efficiencies of three DOM fractions in L1 using PFS or PAC as coagulants. Coagulation-sedimentation process more readily removed organic matters of high MW and high hydrophobicity than their low-MW, hydrophilic counterparts. This observation correlated with the literature 

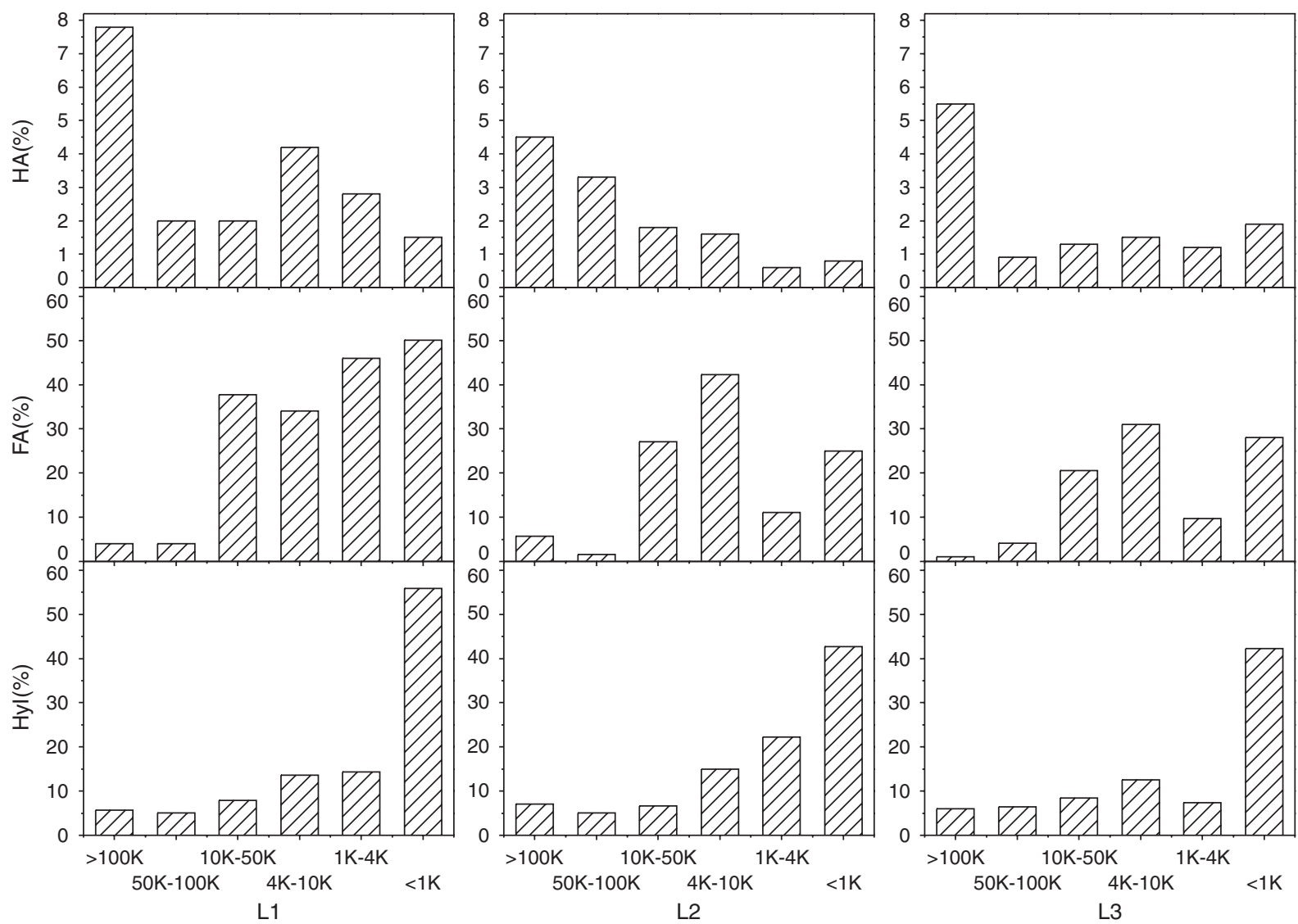

Fig. 4 - The molecular weight distributions of the HA, FA and HyI fractions in leachates.

Table 5 - The SUVA254 of HA, FA and Hyl in different MW ranges in recirculated leachates (Unit: $1 \mathrm{mg}^{-1} \mathrm{~m}^{-1}$ )

\begin{tabular}{|c|c|c|c|c|c|c|c|c|c|}
\hline \multirow[t]{2}{*}{ Molecular weight (Da) } & \multicolumn{3}{|c|}{ L1 } & \multicolumn{3}{|c|}{ L2 } & \multicolumn{3}{|c|}{ L3 } \\
\hline & HA & FA & HyI & HA & FA & HyI & HA & FA & HyI \\
\hline$>100 \mathrm{k}$ & 4.27 & 2.85 & 1.38 & 4.65 & 3.88 & 1.83 & 4.50 & 3.18 & 1.55 \\
\hline $50-100 \mathrm{k}$ & 4.22 & 2.85 & 1.37 & 4.51 & 3.80 & 1.84 & 4.26 & 3.27 & 1.55 \\
\hline $10-50 \mathrm{k}$ & 4.13 & 2.70 & 1.43 & 3.69 & 3.46 & 1.87 & 3.47 & 2.72 & 1.63 \\
\hline $4-10 \mathrm{k}$ & 3.37 & 2.62 & 1.53 & 3.15 & 2.48 & 1.78 & 2.85 & 2.13 & 1.56 \\
\hline $1-4 \mathrm{k}$ & 2.92 & 2.53 & 1.51 & 2.58 & 2.21 & 1.68 & 2.19 & 1.72 & 1.36 \\
\hline
\end{tabular}

findings (Laine et al., 1990; Edzwald and Tobiason, 1999), which might be contributable to the anionic polyelectrolytelike characteristics of humic substances yielded by weakly acidic functional groups such as carboxylic groups for easy flocculation (O'Melia et al., 1999). Moreover, PFS was noted more efficient to remove DOM than PACl, especially for the DOM with MW between $1 \mathrm{k}$ and $10 \mathrm{kDa}$, although both coagulants performed poorly with the HyI fraction. The SUVA $_{254}$ of the HA, FA and Hyl fractions of the supernatant after coagulation-sedimentation were $1.62 \mathrm{lmg}^{-1} \mathrm{~m}^{-1}$, $1.451 \mathrm{mg}^{-1} \mathrm{~m}^{-1}$ and $0.91 \mathrm{lmg}^{-1} \mathrm{~m}^{-1}$ by $\mathrm{PFS}$, and $2.121 \mathrm{mg}^{-1} \mathrm{~m}^{-1}, 2.041 \mathrm{mg}^{-1} \mathrm{~m}^{-1}$ and $1.151 \mathrm{mg}^{-1} \mathrm{~m}^{-1}$ by $\mathrm{PACl}$, respectively. Hence, the substances of high $\mathrm{SUVA}_{254}$ were considerably removed by coagulation-sedimentation. How- ever, the BOD values of treated supernatants were $50 \mathrm{mgl}^{-1}$ by $\mathrm{PFS}$ (BOD/COD ratio of 0.05-0.08) and $135 \mathrm{mgl}^{-1}$ by PACl (BOD/ COD ratio of $0.07-0.12)$. No significant $\mathrm{BOD} / \mathrm{COD}$ ratio improvement was noted for L1 (0.05-0.1). Restated, although the coagulation-sedimentation could efficiently remove COD (DOM) from bioreactor landfill leachate, the biodegradability of remaining substance was not improved. Moreover, with either coagulant, large amount of sludge was produced that required subsequent treatment.

\subsubsection{Electrolysis}

Electrolysis test revealed that the COD of leachate L1 was decreased from $1450 \mathrm{mgl}^{-1}$ to $810 \mathrm{mgl}^{-1}$ (removal ratio of $56 \%$ ) and BOD reached $230 \mathrm{mgl}^{-1}$ after 90 -min electrolysis. 


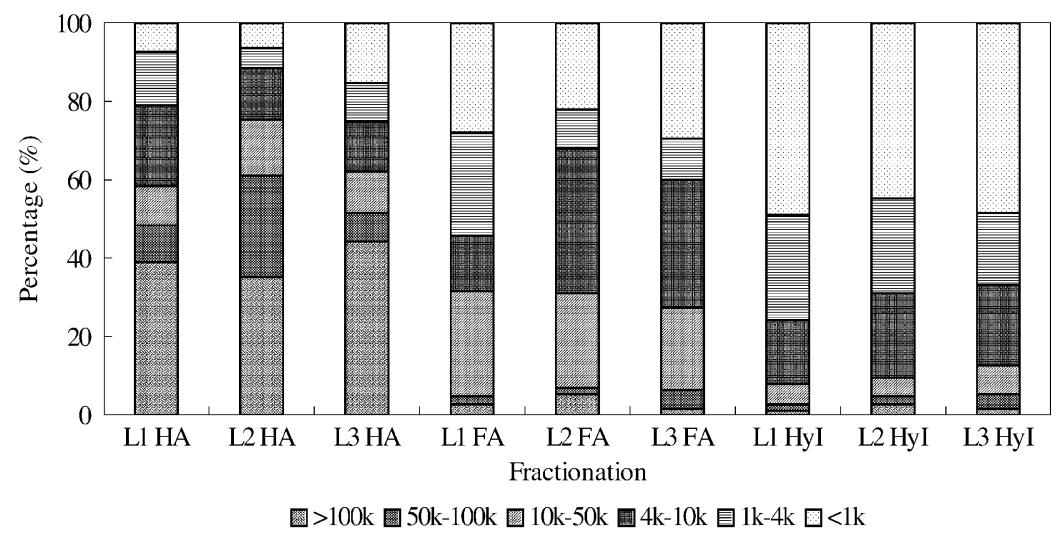

Fig. 5 - The MW distributions of HA, FA and HyI fractions in recirculated leachates.
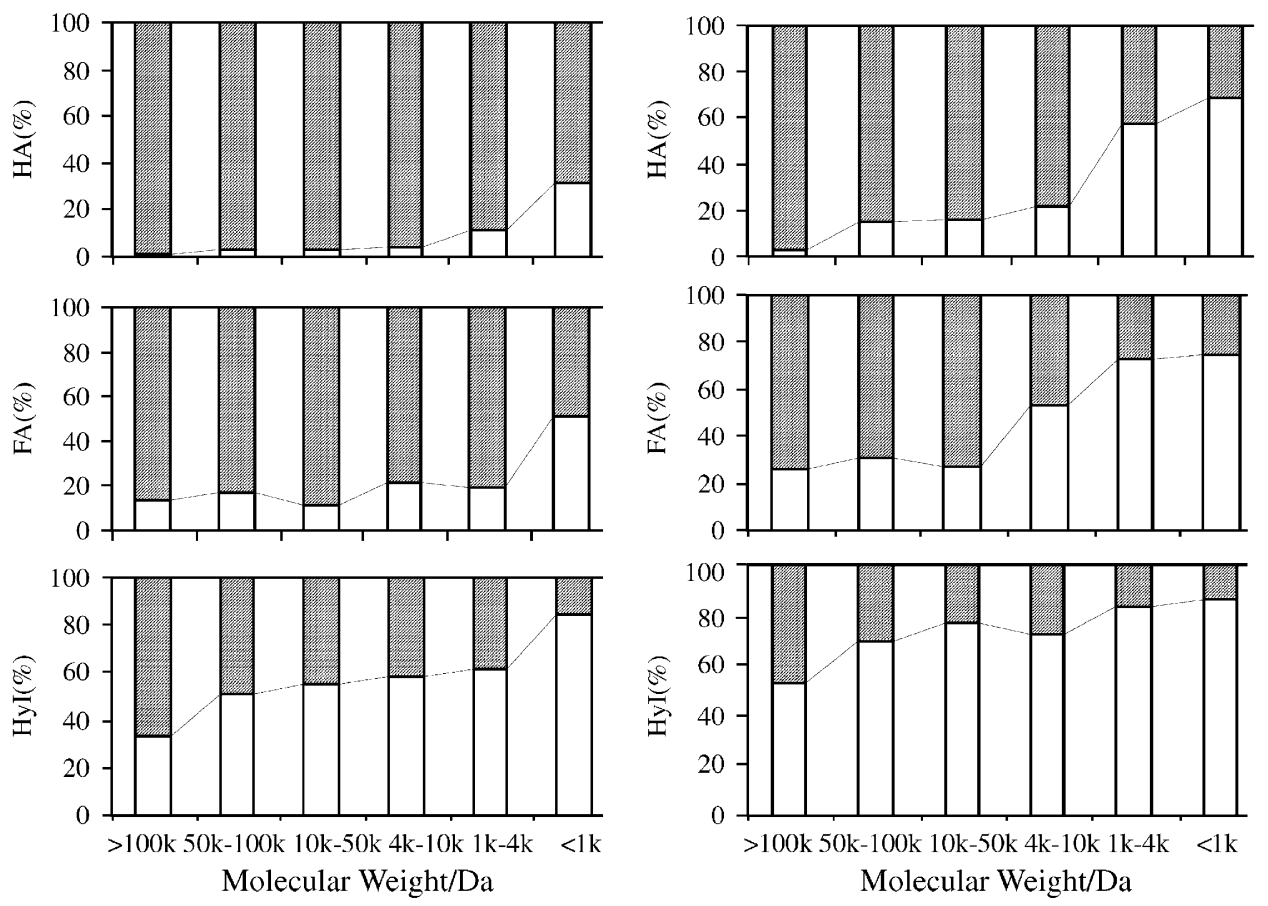

(a)

$\square$ Remains 圆 Removal

(b)

$\square$ Remains 四 Removal

Fig. 6 - The changes of HA, FA and HyI fractions of recirculated leachate at different MW range through coagulation by the addition of coagulant. (a) PFS, (b) PACl.

The corresponding BOD/COD ratio of the effluent after electrolysis was increased from $0.05-0.1$ to around 0.3 . The HA, FA and HyI fractions of the residual suspension were measured and shown in Fig. 7. Similar to the effect of coagulation-sedimentation process discussed above, electrolysis was noted to remove more readily the organic matters of high-MW and of high hydrophobicity. Chiang et al. (2000) also commented that HA and high-MW organic compounds could be effectively removed by electrolysis. Moreover, electrolysis was noted to be more efficient in HyI degradation than coagulation-sedimentation process in Fig. 6. Surely such a comparison was not fair since the two tests were not conducted at their correspondingly optimal conditions and the different operational costs should be accounted for. The SUVA $_{254}$ of the HA, FA and HyI fractions of the electrolyzed leachates were also measured, being $0.861 \mathrm{mg}^{-1} \mathrm{~m}^{-1}$,
$0.771 \mathrm{mg}^{-1} \mathrm{~m}^{-1}$ and $0.441 \mathrm{mg}^{-1} \mathrm{~m}^{-1}$, respectively. Electrolysis had thereby considerably reduced the aromatic contents of the recirculated leachate, particularly the HA fraction, hence enhancing their biodegradability.

Compared with coagulation-sedimentation, the potential to degrade more HyI and to yield treated suspension with DOM of higher biodegradability are a benefit to apply electrolysis process for recirculated leachate from bioreactor landfills.

\section{Conclusions}

This study compared the characteristics of the dissolved organic matter (DOM) in leachate from simulated bioreactor landfill columns with or without presence of trace oxygen. The original leachate (LN) was a strong liquor comprising TOC 

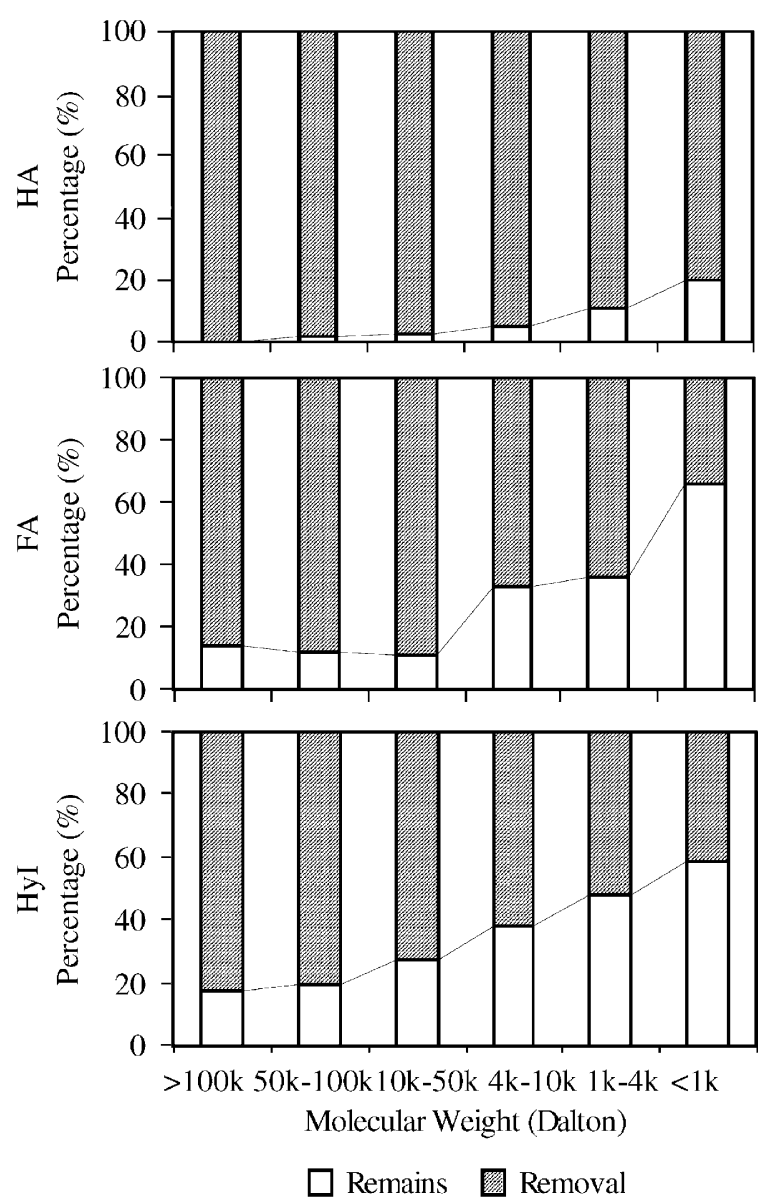

Fig. 7 - The change of HA, FA and HyI fractions from recirculated leachate through electrolysis.

of $15700 \mathrm{mgl}^{-1}$ (96.7\% dissolved organic carbon with $77 \%$ as HyI fraction), mainly comprising HyI and FA fractions with $\mathrm{MW}<1 \mathrm{kDa}$. Leachate recirculation through bioreactor landfill reduced HA from 87 to $12-20 \mathrm{mgl}^{-1}$, FA from 3390 to $96-178 \mathrm{mgl}^{-1}$, and HyI from 11700 to $87-115 \mathrm{mgl}^{-1}$, with higher degradation efficiency achievable for intermittentaeration mode (L2) or natural aeration mode (L3) than conventional mode (L1). The FA and HyI fractions with $\mathrm{MW}<4 \mathrm{k}$ Da were more readily removed with the presence of oxygen. Meanwhile, the aromatic extent increased and BOD/COD decreased after leachate recirculation, indicating poor biodegradability of the recirculated leachate.

The removal efficiencies of the DOM remained in leachate using coagulation-sedimentation or electrolysis processes were examined. Coagulation-sedimentation tests revealed that poly ferric sulphate (PFS) could remove more COD (58.1\%) from leachate than polyaluminum chloride (PACl) $(22.9 \%)$, particularly on the HA fraction with $\mathrm{MW}>10 \mathrm{kDa}$. Although the remaining supernatant mainly comprised HyI of low MW, the corresponding BOD/COD ratio was not improved through coagulation.

Electrolysis test revealed that the COD removal ratio from leachate L1 was $56 \%$ with a significant increase in BOD/COD ratio (from $0.05-0.1$ to 0.3 ) after 90 -min electrolysis which also effectively removed HA of $\mathrm{MW}>10 \mathrm{kDa}$. The corresponding
SUVA $_{254}$ of the treated leachate was also considerably reduced. This improvement in biodegradability of suspension after electrolysis presents a major benefit to apply the electrochemical treatment to degrade leachates from bioreactor landfills.

\section{Acknowledgements}

The authors greatly acknowledge the National High Technology Research and Development Program of China (No. 2001AA644010, No. 2003AA644020, and No. 2005AA644010) for support.

R E F E R E N C E S

Amokrane, A., Comel, C., Veron, J., 1997. Landfill leachates pretreatment by coagulation-flocculation. Water Res. 31, 2775-2782.

Baumgarten, G., Seyfried, C.F., 1996. Experiences and new developments in biological pretreatment and physical posttreatment of landfill leachate. Water Sci. Technol. 34 (7-8), 445-453.

Chiang, C.L., Chang, J.E., Tseng, S.C., 1997. Electrochemical oxidation pretreatment of refractory organic pollutants. Water Sci. Technol. 36 (2-3), 123-130.

Chiang, L.C., Chang, J.E., Wen, T.C., 1995. Indirect oxidation effect in electrochemical oxidation treatment of landfill leachate. Water Res. 29, 671-678.

Chiang, L.C., Chang, J.E., Wen, T.C., 2000. Destruction of refractory humic acid by electromechanical oxidation process. Water Sci. Technol. 42 (3-4), 225-232.

Christensen, J.B., Jensen, D.L., Gron, C., Filip, Z., Christensen, T.H., 1998. Characterization of the dissolved organic carbon in landfill leachate-polluted groundwater. Water Res. 32, 125-135.

Cossu, R., Polcaro, A., Lavagnolo, M., Mascia, M., Palmas, S., Renoldi, F., 1998. Electrochemical treatment of landfill leachate: oxidation at $\mathrm{Ti} / \mathrm{PbO}_{2}$ and $\mathrm{Ti} / \mathrm{SnO}_{2}$ anodes. Environ. Sci. Technol. 32, 3570-3573.

Dong, B.Z., Cao, D.W., Fan, J.C., 2001. Characteristics of changes in distribution of molecular weight of dissolved organics in Huangpu River water source. Acta Scientiae Circumstantiae 21, 553-556.

Edzwald, J.K., Tobiason, J.E., 1999. Enhanced coagulation: US requirements and a broader view. Water Sci. Technol. 40 (9), 63-70.

He, P.J., Feng, X.W., Shao, L.M., 2003. Management of the Municipal Solid Wastes. Science Press, Scientific Publishing Center, Beijing, PR China.

He, P.J., Shao, L.M., Qu, X., Li, G.J., Lee, D.J., 2005. Effects of feed solutions on refuse hydrolysis and landfill leachate characteristics. Chemosphere 59 (6), 837-844.

Kalbitz, K., Solinger, S., Park, J.H., Michalzik, B., Malzner, E., 2000. Controls on the dynamics of dissolved organic matter in soils: a review. Soil Sci. 165, 277-304.

Kang, K.H., Shinb, H.S., Parka, H., 2002. Characterization of humic substances present in landfill leachates with different landfill ages and its implications. Water Res. 36, 4023-4032.

Laine, J.M., Clark, M.M., Mallevialle, J., 1990. Ultrafiltration of lake water: effect of pretreatment on the partitioning of organics, THMFP and Flux. J. Am. Waterworks Assoc. 82, 82-87.

Leenheer, J.A., Croue, J.P., 2003. Characterizing aquatic dissolved organic matter. Environ. Sci. Technol. 37, 18-26. 
Li, C.W., Korshin, G.V., Benjamin, M.M., 1998. Monitoring DBP formation with differential UV spectroscopy. J. Am. Water Works Assoc. 90, 88-100.

Li, S., Zhang, X.J., Fan, X.J., 2003. Orangic matter of various molecular weight fractions in soure water. Acta Scientiae Circumstantiae 23, 327-331.

Luo, X.H., Cao, L.L., Wang, Z.S., 1998. Study on the removal of different molecular weight organics by water purification process. China Environ. Sci. 18, 341-344.

O'Melia, C.R., Becker, W.C., Au, K.K., 1999. Removal of humic substances by coagulation. Water Sci. Techol. 40 (9), 47-54.

State Environmental Protection Administration of China, 1997. Standard for pollution control on the landfill site for domestic waste, China, GB 16889-1997.

Tatsi, A.A., Zouboulis, A.I., Matis, K.A., 2003. Coagulation-flocculation pretreatment of sanitary landfill leachates. Chemosphere 53, 737-744.

Thornton, S.F., Bright, M.I., Lerner, D.N., Tellam, J.H., 2000. Attenuation of landfill leachate by UK Triassic sandstone aquifer materials. 2. Sorption and degradation of organic pollutants in laboratory columns. J. Contaminant Hydrol. 43, 355-383.
Thurman, E.M., Malcolm, R.L., 1981. Preparative isolation of aquatic humic substances. Environ. Sci. Technol. 15, 463-466.

Tsai, C.T., Lin, S.T., Shue, Y.C., Su, P.L., 1997. Electrolysis of soluble organic matter in leachate from landfills. Water Res. 31, 3073-3081.

Vlyssides, A.G., Karlis, P.K., Mahnken, G., 2003. Influence of various parameters on the electrochemical treatment of landfill leachates. J. Appl. Electrochem. 33, 155-159.

Wang, G.M., Zhou, L.X., 2003. Dynamics of dissolved organic matter in terrestrial ecosystem and its environmental impact. Chin. J. Appl. Ecol. 14, 2019-2025.

Yoon, J., Cho, S., Cho, Y., Kim, S., 1998. The characteristics of coagulation of fenton reaction in the removal of landfill leachate organics. Water Sci. Technol. 38 (2), 209-214.

Yu, X.H., He, P.J., Shao, L.M., Li, G.J., 2004. Effect on nitrogen component in leachate under different air conditions in landfill layers. J. Tongji Univ. (Natural Science Edn.) 32, 741-744.

Zhang, H., Huang, C.P., 2002. Treatment of landfill leachate by fenton oxidation process. Chin. J. Chem. Eng. 10, 128-131.

Zhang, X.X., He, P.J., Shao, L.M., Li, G.J., 2004. Effects on landfill methane production by different leachate recirculation operations. Acta Scientiae Circumstantiae 24, 304-308. 